\title{
PENGARUH VARIASI JUMLAH BLADE TERHADAP AERODINAMIK PERFORMAN PADA RANCANGAN KINCIR ANGIN 300 Watt
}

\author{
I Made Adi Sayoga, I Kade Wiratama, I Made Mara, Agus Dwi Catur \\ Teknik Mesin Universitas Mataram \\ Made.Mara@gmail.com
}

\begin{abstract}
In some areas in Indonesia, such as: the southern part of Sumatra until Nusa Tenggara, wind velocity is large enough to be used as a wind power plant with a range of 5-15 knots of wind speed equivalent 2.5-7.5 m / s. However, wind energy has not yet been developed, there are only a wind power plant with a total capacity of $1.4 \mathrm{GW}$ in Indonesia. Mostly, instruments wind power is basically intended for European plains wind speed range of 10-30 knots. So that the necessary adjustments for the Indonesian state that smaller wind speed in order to optimize the system work.

The purpose of this study was to determine the influence of the number of blades and wind speed on electric power generated by a horizontal axis wind turbine. The type of blade used is arched plate and fitted with a pitch angle of $30 \mathrm{o}$. Key issues to be examined in this study is how the influence of the number of blades $(3,4$, and 5 blade) and wind speed $(3 \mathrm{~m} / \mathrm{s}, 4 \mathrm{~m} / \mathrm{s}$ and $5 \mathrm{~m} / \mathrm{s}$ ) to the performance of horizontal axis wind turbines.

These results indicate that the number of blade 5 gives rpm, torque, power and highest $\mathrm{Cp}$ compared to the number of blade 3 and 4 . Similarly, the wind speed of $5 \mathrm{~m} / \mathrm{s}$ provide better performance on any number of blade. The highest power obtained on the number of blades 5 and wind speed of $5 \mathrm{~m} / \mathrm{s}$ with an average of 23.775 Watt. The highest Cp values obtained on the number of blades 5 and wind speed of $5 \mathrm{~m} / \mathrm{s}$ which is an average of 0.4 .
\end{abstract}

Kata kunci; blade, arched plate, wind turbine, blade, wind energy.

\section{PENDAHULUAN}

Konsumsi energi dewasa ini semakin meningkat, dan terfokus kepada penggunaan energi fosil yaitu bahan bakar minyak yang terbatas dan harganya semakin meningkat. Pada sisi lain tersedia berbagai jenis energi alternatif yang dapat diperbaruhi, jumlahnya melimpah serta tersedia sepanjang masa dan juga tidak menimpulkan polusi antara lain energi air, energi matahari, energi biomasa, energi angin dan lain lain. Pengembangan energi terbarukan dapat dijadikan unggulan untuk mendampingi atau mensubstitusikan penggunaan bahan bakar minyak. Pengkajian energi ini mutlak dilakukan agar tidak terjadi krisis energi. Melalui kajian mesin konversi energi maka energi terbarukan di Indonesia dapat dimanfaatkan secara optimal untuk kebutuhan energi di dalam menunjang keberlangsungan pembangunan dan kebutuhan manusia di bidang energy, [1], [2]..

Turbin angin sumbu horizontal (TASH) memiliki poros rotor utama dan generator listrik di puncak menara. Turbin berukuran kecil diarahkan oleh sebuah baling-baling angin (baling-baling cuaca) yang sederhana, sedangkan turbin berukuran besar pada umumnya menggunakan sebuah sensor angin yang digandengkan ke sebuah servo motor. Karena turbulensi menyebabkan kerusakan struktur menara, dan realibilitas begitu penting, sebagian besar TASH merupakan mesin upwind ( melawan arah angin). Meski memiliki permasalahan turbulensi, mesin downwind ( searah angin) dibuat karena tidak memerlukan mekanisme tambahan agar mereka tetap sejalan dengan angin, dan karena di saat angin berhembus sangat kencang, bilah-bilahnya bisa ditekuk sehingga mengurangi wilayah tiupan mereka dan dengan demikian juga mengurangi resintensi angin dari bilah-bilah itu. Dikarenakan turbin angin Poros horizontal dapat dioperasikan pada jumlah Blade dan kondisi kecepatan angin yang rendah, maka untuk penilitian kali ini dilakukan kajian jumlah blade terhadap performance turbin angin.

Dalam penelitian ini, masalah yang akan dikaji adalah bagaimanakah pengaruh jumlah blade dan radius chord terhadap performansi Turbin Angin Sumbu Horizontal 
(TASH) di tinjau dari daya dan putaran yang dimiliki oleh turbin angin serta potensi pengembangan turbin angin sumbu horizontal bila dikaitkan dengan potensi angin yang ada di daerah NTB.

Adapun tujuan khusus dari penelitian ini adalah untuk mengetahui pengaruh jumlah blade terhadap putaran, torsi, daya, Coefficient Power (CP), dan Tip Speed Ratio $(\lambda)$ turbin angin serta mengetahui pengaruh radius chord terhadap putaran, torsi, daya, Coefficient Power (CP), dan Tip Speed Ratio (入) turbin angin.

Radius cord pada sudu turbin angin pada penelitian ini merupakan upaya dalam memperbesar gaya dorong angin yang digunakan untuk memutar sudu sehingga inovasi ini dapat memperbesar daya guna pemanfaatan energi kecepatan angin. Maka dalam penelitian ini dilakukan dengan merancang bentuk profil, memperbesar radius chord dan memperbanyak jumlah blade pada turbin dapat meningkatkan unjuk kerja Turbin Angin Sumbu Horizontal (TASH). Penelitian ini akan menghasilkan bentuk profile blade yang optimal digunakan pada kecepatan angin yang rendah dan dapat digunakan pada generator magnet permanen sehingga dapat dijadikan acuan lebih lanjut dalam meneruskan kerangka penelitian yang sesuai dengan road map kelompok riset energi bayu yaitu pemanfaatan energi bayu kecepatan rendah menjadi energi listrik DC, Pengembangan design blade turbin angin kecepatan rendah, Aplikasi Generator DC Magnet permanen pada turbin angin.

\section{TINJAUAN PUSTAKA}

Potensi angin di NTB yang berada di kawasan Indonesia Timur, tidak bisa lepas dari pantai. Seperti kita tahu, kawasan pantai memiliki kecepatan angin yang lebih tinggi ketimbang daratan. Listrik pun dapat dibangkitkan dengan energi angin. Syarat untuk membangkitkan listrik berkapasitas 10 kW dibutuhkan minimal angin berkecepatan 2,5 sampai 4 meter per detik. Angin di wilayah NTB mempunyai kecepatan antara 3,4-5,3 meter per detik. Berarti daerah ini memang menyimpan potensi energi angin yang sayangnya masih belum diolah secara maksimal, [3].

Mukund R. Patel menambahkan yang dikutip oleh [3] menjelaskan, seperti yang terlihat dalam persamaan daya angin, keluaran daya dari turbin angin bervariasi linear dengan daerah yang melawati rotor blade. Untuk turbin sumbu horizontal, daerah yang melewati rotor blade adalah:

$$
\mathrm{A}=\frac{\pi}{4} \mathrm{D}^{2}
$$

dimana, $\mathrm{D}$ adalah diameter rotor

Daya angin maksimum yang dapat diekstrak oleh turbin angin dengan luas sapuan rotor $\mathrm{A}$ adalah:

$P=\frac{16}{27} \frac{1}{2} \rho \mathrm{AV}^{3}$

[4],[5] menambahkan, Angka 16/27 = (59.3\%) ini disebut batas Betz (Betz limit). Angka ini secara teori menunjukkan efisiensi maksimum yang dapat dicapai oleh rotor turbin angin tipe sumbu horisontal. Pada kenyataannya karena ada rugi-rugi gesekan dan kerugian di ujung blade, efisiensi aerodinamik dari rotor, nrotor ini akan lebih kecil lagi yaitu berkisar pada harga maksimum 0.45 saja untuk blade yang dirancang dengan sangat baik. Maka daya yang dapat diserap oleh turbin angin menjadi:

$$
P=C p \frac{1}{2} \rho A V^{3}
$$

Daya adalah energi per satuan waktu. Daya angin berbanding lurus dengan kerapatan udara, dan kubik kecepatan angin, seperti diungkapkan dengan persamaan berikut:

Daya Angin $P=\frac{1}{2} \rho A V^{3}$

Daya Turbin $P=T . \omega$

dimana :

$$
\omega=2 \cdot \pi \cdot \frac{\mathrm{n}}{60}
$$

dimana,

$P$ = Daya (Watt)

$\rho=$ Massa jenis angin $\left(\mathrm{Kg} / \mathrm{m}^{3}\right)$

$A=$ Luas Penampang $\left(\mathrm{m}^{2}\right)$

$V=$ Kecepatan Angin $(\mathrm{m} / \mathrm{s})$

$\mathrm{T}=$ Torsi $(\mathrm{Nm})$

$\omega=$ Kecepatan sudut $(\mathrm{rad} / \mathrm{s})$

$\mathrm{n}=$ Putaran (rpm)

Tip speed ratio adalah perbandingan kecepatan ujung rotor terhadap kecepatan angin. Untuk kecepatan angin nominal tertentu, tip speed ratio akan berpengaruh pada kecepatan rotor. Turbin angin tipe lift akan memiliki tip speed ratio yang relatif lebih besar dibandingkan dengan turbin angin drag. Tip speed ratio dihitung dengan persamaan :

$$
\lambda=\frac{2 . \pi \cdot n \cdot r}{60 \times V}
$$

dengan :
$\lambda:$ tip speed ratio
$r$ : jari-jari rotor $(\mathrm{m})$
$\mathrm{n}$ : putaran rotor (rpm) 


\section{$V$ : kecepatan angin $(\mathrm{m} / \mathrm{s})$}

Pada blade turbin angin akan terjadi tegangan geser pada permukaannya ketika kontak dengan udara. Distribusi tegangan geser ini di presentasi dengan adanya gaya tekan (drag) yang arahnya sejajar dengan arah aliran fluida dan gaya angkat (lift) yang arahnya tegak lurus dari arah aliran fluida. Kedua gaya ini menyebabkan blade dapat berputar dan dipengaruhi oleh bentuk blade, luas permukaan bidang dan kecepatan angin. Sebagai contoh sebuah airfoil adalah penampang potongan sayap pesawat dengan bidang sejajar kecepatan terbang (arus bebas) dan tegak lurus sayap, [5].

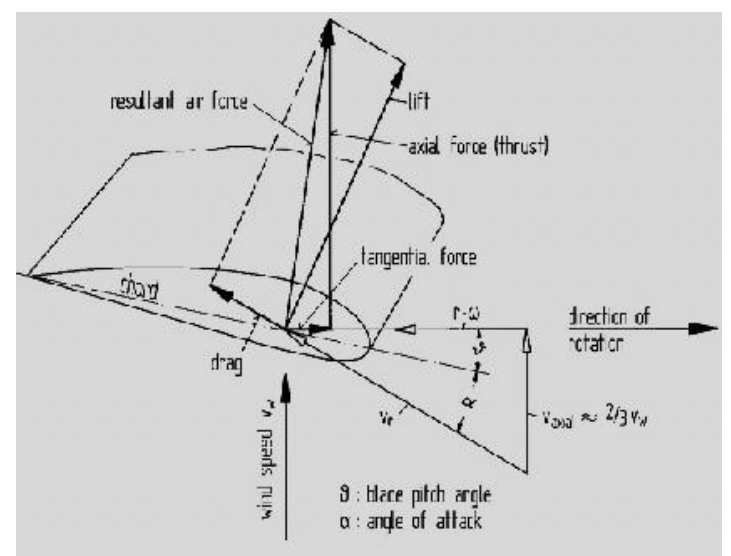

Gambar 1. Penampang Blade.

Untuk karaktersitik bentuk blade geometris, beberapa parameter dari perhitungan berdasarkan dari teknologi pesawat terbang sudah digunakan dalam penentuan beberapa perhitungan dalam penentuan beberpa parameter dari desain blade turbin angin yang mana dapat didefinisikan sebagai berikut:

$$
\begin{aligned}
& \text { Rasio Kepadatan } R r=\frac{\text { Ttl Blde Planform area }}{\text { Luas Sapuan } \text { Rotor }}(\%) \\
& \text { Aspect Ratio }=\frac{(\text { Radius } \text { Rotor })^{2}}{\text { Planform Area dari Blade Rotor }} \\
& \text { Taper }=\frac{\text { Panjang Chord Pada U jung Blade }}{\text { Panjang Chord Pada Daerah Pusat Blade }}
\end{aligned}
$$

Satu masalah dengan definisi parameter-parameter diatas adalah bagaimana menentukan dengan tepat area planform blade dan panjang chord pada akar (root) dari bladenya dan ujung (tip) dari blade yang dibuat serta dalam penentuan daerah “ aerodinamis efektif" dari blade dan panjang chord menjadi kurang jelas.

Bagian blade di dekat hub atau akar dari blade adalah kurang penting ketika rotor turbin angin digunakan untuk menghasilkan daya. Oleh karean itu pada hub blade, aspek aerodinamis dapat dikesampingkan ketika mendesain blade turbin angin sehingga lebih dipertimbangkan untuk mengatasi beban aerodynamic yang terjadi atau lebih jelasnya dipertimbangkan untuk meningkatkan kekuatan blade dan juga kesederhanaan atau memudahkan ketika proses manufaktur. Hal ini berlaku terutama untuk pemanfaatan airfoil yang lebih tebal pada sisi hub bladenya sehingga akan didapat kekuatan blade dan kekakuan yang lebih tinggi dengan bobot yang minimum. Akan tetapi rendahnya kontribusi dalam hal menghasilkan daya pada daerah root dari area baling-baling, tidak harus mengarah pada pembuatan desain yang keliru bahwa, untuk menghemat berat atau biaya dari pembuatan blade maka bagian dari blade (pada bagian rootnya) tidak harus ditiadakan sisi aerodinamisnya, [5].

Penelitian ini merupakan penelitian lanjutan dari kelompok bidang keahlian energi bayu di mana dari hasil beberapa penelitian sebelumnya bahwa kecepatan angin di daerah NTB berkisar $3-5 \mathrm{~m} / \mathrm{s}$. Penelitian bentuk sudu juga sudah menghasilkan bahwa bentuk sudu taper linear merupakan bentuk sudu yang paling optimal untuk kecepatan angin yang rendah. Jumlah sudu yang baik untuk kecepatan angin rendah berkisar antara 4-7 buah sudu, namun profile sudu yang bagaimana yang memberikan $\mathrm{Cp}$ terbaik akan diteliti pada penelitian ini.

Pemanfaatan magnet permanen sebagai generator juga sudah diteliti. Kecepatan putaran poros 800 rpm telah berhasil menghasilkan tegangan listrik sebesar 6 Volt. Tegangan ini telah dicoba untuk menghidupkan lampu led. Namum perlu penelitian lebih jauh mengenai jumlah pole magnet dan jumlah lititan yang bagaimana yang dapat diterapkan agar menghasilkan energi listrik yang paling optimal. Hal ini merupakan penelitian lanjutan dari hasil penelitian ini dan telah sejalan dengan road map Kelompok riset energi bayu. 


\section{METODE PENELITIAN}

A. Tahap Pembuatan

Pada tahap ini peneliti merealisasikan bentuk perancangan yang telah dibuat sebelumnya ke dalam bentuk nyata atau bentuk sebenarnya.

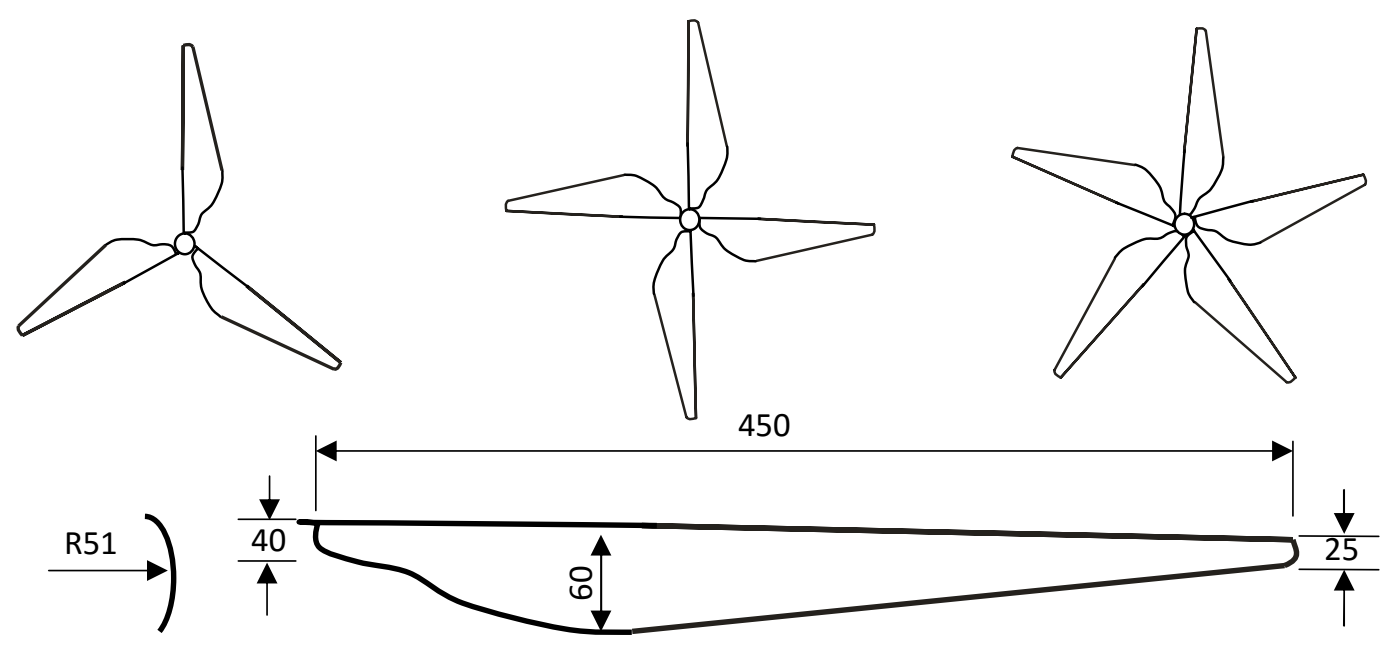

Gambar 2. Dimensi dan profile blade

\section{B. Tahap Pengujian}

Untuk tahap pengujian terakhir dalam penelitian ini adalah tahap pengujian dan pengambilan data. Untuk tahap ini dimulai dengan menaruh wind tunnel didepan kipas dimana wind tunnel ini berfungsi sebagai mentransfer angin menuju blade turbin angin kemudian mengukur kecepatan angin dengan menggunakan anemometer digital. Setelah kecepatan angin dari putaran kipas yang diinginkan telah diperoleh, langkah selanjutnya adalah tahap pengujian dan pengambilan data, tahap pengambilan data ini dilakukan dalam 2 tahap, yaitu jumlah blade dan kecepatan angin. Sebelum pengambilan data dilakukan terlebih dahulu dipersiapkan alat-alat yang akan digunakan pada proses pengambilan data, seperti tachometer, multimeter dan generator.

Pengambilan data pertama dilakukan pada turbin angin yang menggunakan 3 blade kemudian memvariasikan kecepatan angin yang digunakan diantaranya yaitu kecepatan angin $3 \mathrm{~m} / \mathrm{s}$, kecepatan angin 4 $\mathrm{m} / \mathrm{s}$, kecepatan angin $5 \mathrm{~m} / \mathrm{s}$. Proses pengujian ini menggunakan kipas angin untuk mendapatkan sumber angin yang diinginkan. Karena arah angin dari kipas yang menyebar, maka digunakanlah wind tunnel yang bertujuan untuk mengarahkan angin yang dihasilkan oleh kipas, adapun variabel-variabel yang diukur saat pengambilan data adalah kecepatan angin, putaran baling-baling, gaya pengereman.
HASIL DAN PEMBAHASAN

4.1.1 Hubungan Kecepatan Angin Terhadap RPM Pada Variasi Jumlah blade

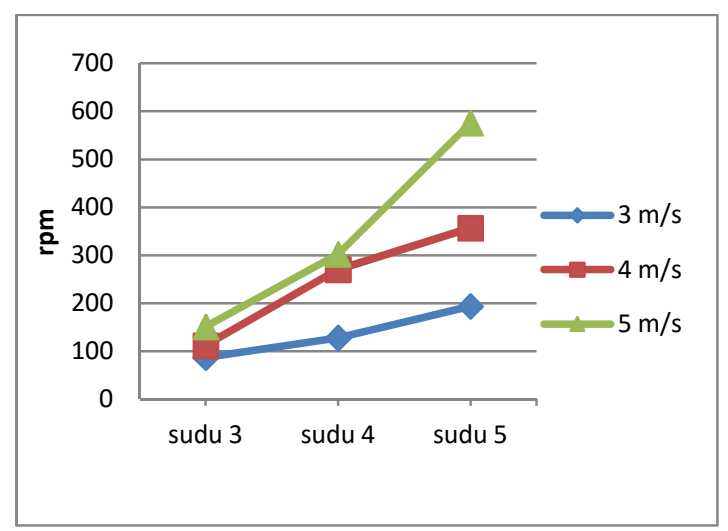

Gambar 3 Hubungan kecepatan angin terhadap rpm pada variasi jumlah blade

Pada gambar.1 dapat dilihat bahwa putaran turbin semakin meningkat seiring dengan semakin meningkatnya kecepatan angin, artinya dengan semakin besar kecepatan angin yang diberikan maka semakin besar pula energi angin yang mengakibatkan sudu turbin berputar. Dengan kata lain energi angin yang dapat dikonversikan turbin menjadi putaran turbin semakin meningkat pula.

Kerapatan antara blade satu dengan yang lainnya juga akan mempengaruhi putaran turbin semakin dekat jarak blade 
dengan blade yang lain akan mempengaruhi jumlah blade penagkap anginnya maka putaran turbin semakin meningkat. Dengan jumlah blade yang sedikit, maka luasan sudu penangkap anginnya sedikit dan kecepatan putaran semakin rendah juga, sebaliknya semakin banyak jumlah blade juga semakin tinggi kecepatan angin maka semakin banyak luasan blade untuk menangkap angin dan juga putaran poros semakin tinggi maka semakin tinggi putarannya. Jumlah blade yang sedikit mengakibatkan angin dengan mudah melewati celah sudu sehingga gaya yang memutar sudu jadi kecil sehingga kecepatan putar blade juga rendah.

\subsubsection{Hubungan Kecepatan Angin dan Variasi Jumlah Sudu Terhadap TSR}

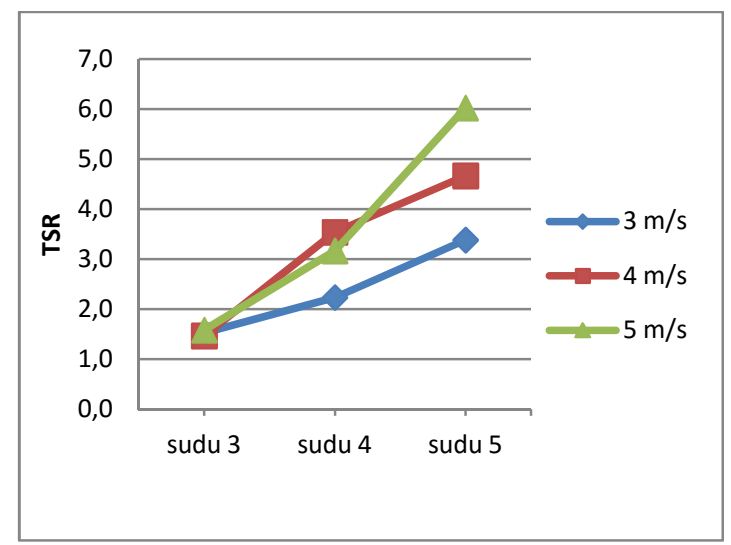

Gambar 4 Grafik hubungan kecepatan angin terhadap TSR

Pada gambar 4 dapat dilihat bahwa tip speed ratio semakin meningkat seiring dengan semakin meningkatnya kecepatan angin, artinya semakin besar kecepatan angin yang diberikan maka semakin besar pula energi yang diberikan oleh angin terhadap turbin sehingga energi yang dapat dikonversikan turbin menjadi tip speed ratio semakin meningkat pula.

TSR merupakan perbandingan antara kecepatan tangensial ujung blade terhadap kecepatan angin actual. TSR memiliki hubungan yang erat dengan efisiensi, dengan mengoptimalkan design blade. TSR yang semakin tinggi akan meningkatkan getaran yang dapat menimbulkan kebisingan dan membutuhkan blade yang semakin kokoh untuk mengatasi besarnya gaya sentrifugal. TSR pada kecepatan angin tertentu diusahakan setinggi mungkin karena turbin angin akan dapat menghasilkan lebih banyak daya akibat putaran poros yang semakin besar. Namun hal ini memerlukan rancangan system yang harus lebih kuat agar tidak rusak.

Jika rotor turbin angin berputar lambat, sebagain besar angin akan lewat begitu saja melalui celah blade, namun sebaliknya jika rotor turbin bergerak terlalu cepat maka blade yang berputar seolah-olah seperti tembok penghalang dan angin sulit melewatinya. TSR yang terlalu kecil dan terlalu besar tidak baik, oleh karena itu blade harus dirancang untuk mendapatkan TSR yang optimum pada daya turbin yang maksimal. TSR optimum tergantung pada jumlah sudu, makin sedikit jumlah sudu semakin tinggi putaran turbin yang dibutuhkan untuk mendapatkan daya maksimum.

Dari ketiga variasi jumlah blade yang dilakukan nilai tip speed ratio turbin maksimal terbesar pada kecepatan angin $5 \mathrm{~m} / \mathrm{s}$ yang dihasilkan oleh 5 blade. Hal ini terjadi karena semakin banyak jumlah blade dan semakin tinggi kecepatan angin maka tip speed ratio juga akan semakin tinggi. Semakin sedikit jumlah blade dan semakin kecil kecepatan angin maka luasan sudu penangkap anginnya sedikit dan kecepatan tip speed ratio juga semakin rendah.

\subsubsection{Hubugan Kecepatan Angin Terhadap Daya Poros Pada Variasi Jumlah Blade}

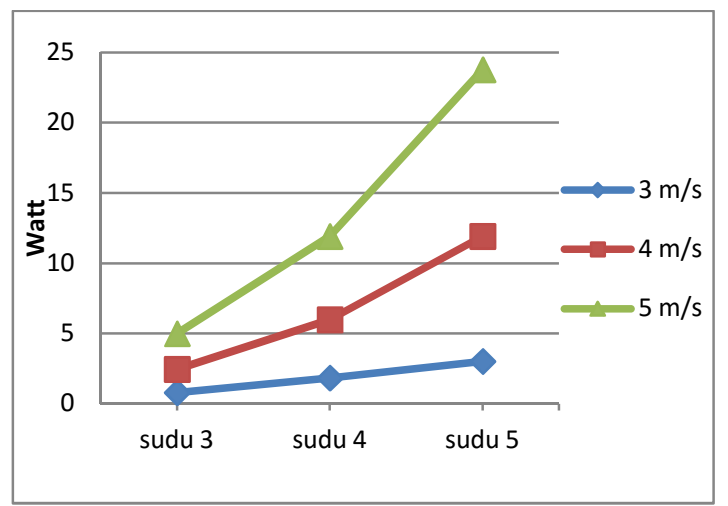

Grafik. 5 Hubungan Jumlah sudu terhadap daya output

Dari gambar 5 dapat dilihat bahwa turbin yang menggunakan 3 blade pada kecepatan angin $3 \mathrm{~m} / \mathrm{s}$ mempunyai nilai yang di hasilkan oleh daya poros 0,789 watt. Sedangkan dengan turbin yang menggunakan 5 blade dimana nilai yang dihasilkan oleh daya output sebesar 4,988 watt. Semakin tinggi kecepatan angin dan semakin banyak jumlah blade maka semakin tinggi daya poros yang dihasilkan. 
Dan turbin yang menggunakan 5 blade juga pada kecepatan angin yang sama dimana jumlah lampu let yang dinyalakan sebanyak 36 lampu let. Semakin tinggi kecepatan angin dan semakin banyak jumlah blade maka beban lampu yang dinyalakan juga semakin banyak dan semakin tinggi daya output yang dihasilkan oleh generator maka semakin tinggi pula beban lampu yang dinyalakan.

Dari ketiga variasi jumlah blade yang dilakukan nilai daya output generator turbin maksimal terbesar pada kecepatan angin 5 $\mathrm{m} / \mathrm{s}$ yang dihasilkan oleh 5 blade dengan nilai daya output poros turbin sebesar 23,775 watt.

\section{KESIMPULAN DAN SARAN}

\section{Kesimpulan}

Dari hasil penelitian yang telah dilakukan dapat diambil beberapa kesimpulan sebagai berikut :

1. Jumlah blade 5 memberikan nilai rata-rata rpm yang lebih tinggi dibandingkan dengan 3 blade dan 4 blade. Rpm tertinggi didapat pada jumlah blade 5 dan kecepatan angin $5 \mathrm{~m} / \mathrm{s}$ yaitu rata-rata 576 rpm.

2. Jumlah blade 5 memberikan nilai rata-rata torsi dan daya yang lebih tinggi dibandingkan dengan 3 blade dan 4 blade. Daya tertinggi didapat pada jumlah blade 5 dan kecepatan angin $5 \mathrm{~m} / \mathrm{s}$ yaitu rata-rata 23,775 Watt

3. Nilai rata-rata TSR berkisar antara 1,5 sampai 6,0 .

4. Jumlah blade 5 memberikan nilai rata-rata $\mathrm{Cp}$ yang lebih tinggi dibandingkan dengan 3 blade dan 4 blade. Cp tertinggi didapat pada jumlah blade 5 dan kecepatan angin $5 \mathrm{~m} / \mathrm{s}$ yaitu rata-rata 0,4

\section{Saran}

Perlu penelitian lebih lanjut untuk mengenai pengaruh jumlah blade dan kecepatan angin dengan sudut pitch berbeda sehingga diperoleh sudut pitch yang terbaik.

\section{Daftar Pustaka}

[1] Daryanto, Y., F. A. Yohanes dan F. Hasim., ( 2005) Potensi, Peluang dan Tantangan Energi Angin di Indonesia, BPPT Tangerang.

[2] Alamsyah, H., 2007, Pemanfaatan Turbin Angin Dua Sudu Sebagai Penggerak Mula Alternator Pada Pembangkit Listrik Tenaga Angin. Semarang :Universitas Negeri Semarang

[3] Ariyanto, F., 2012, Pengaruh Kecepatan Angin Dan Variasi Jumlah Sudu Terhadap Unjuk Kerja Turbin Angin Poros Horizontal. Mataram: Universitas Mataram

[4] Daryanto, Y; 2007, Kajian Potensi angin Untuk Pembangkit Listrik Tenaga Bayu. Yogyakarta : BALAI PPTAGG - UPTLAG

[5] Hau, E. 2006. Wind Turbines Fundamentals, Technologies, application, Economics. Edisi Kedua. Germany: Springer 


\section{LAMPIRAN}
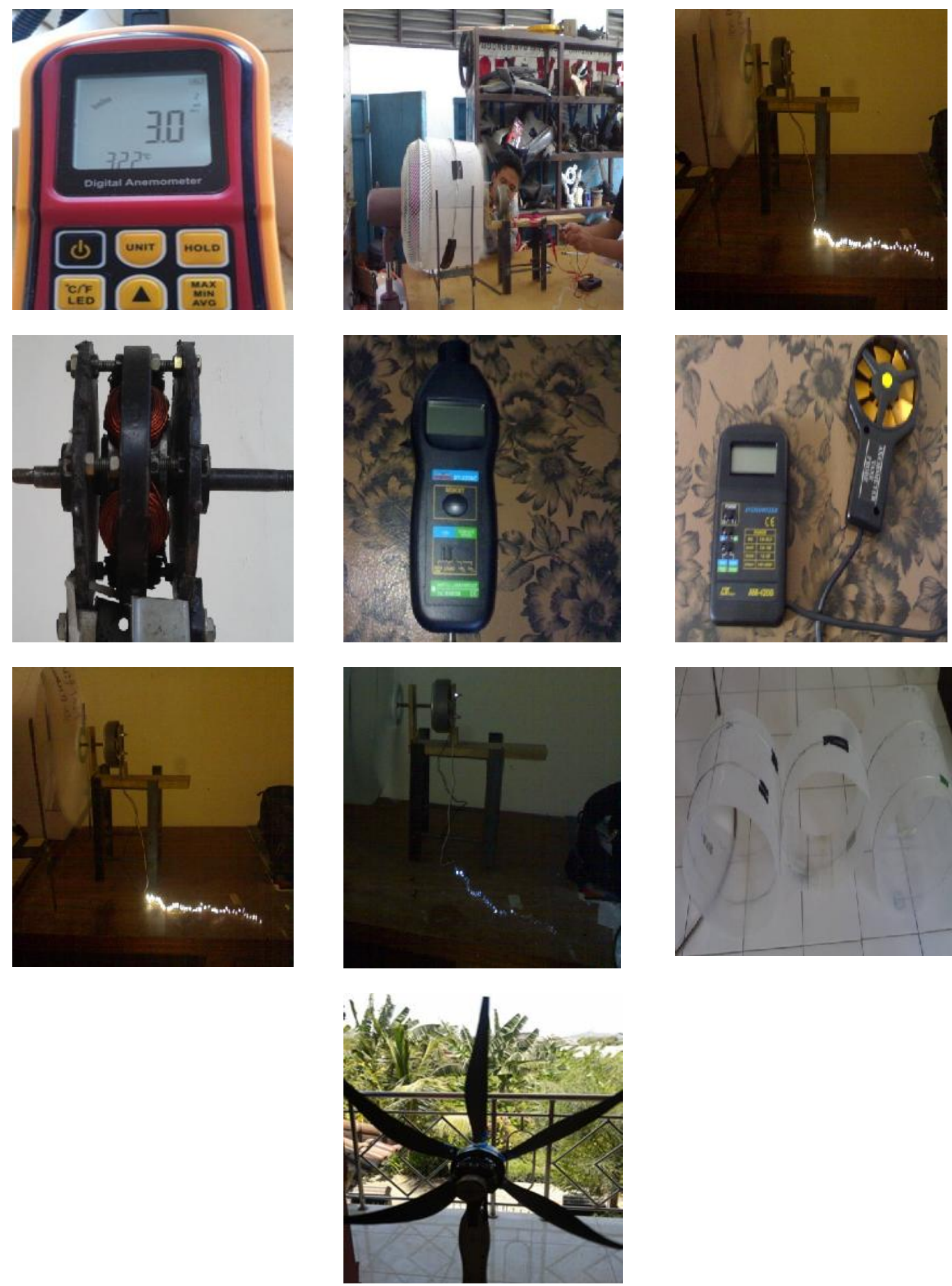